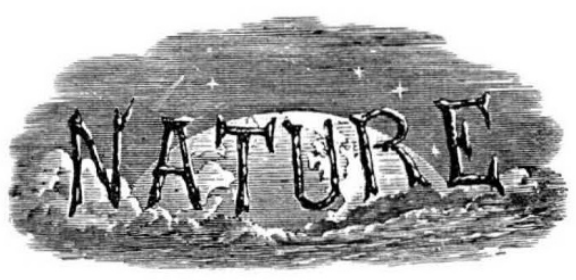

SATURDAY, APRIL I6, I932

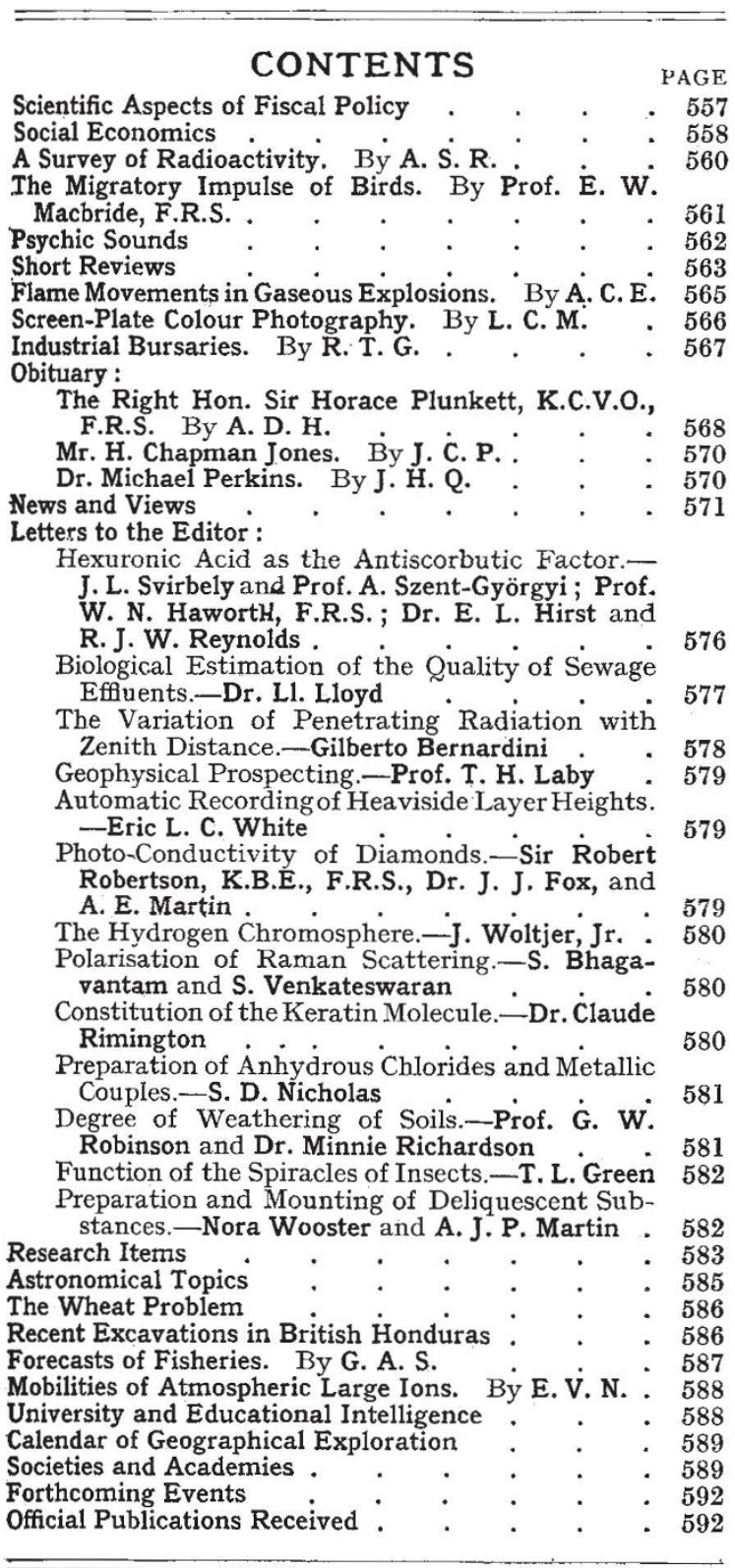

Editorial and Publishing Offices:

MACMILLAN \& CO., LTD.

ST. MARTIN'S STREET, LONDON, W.C.2

Telephone Number: WHITEHALL 8831

Telegraphic Address: PHUSIS, LESQUARE, LONDON

No. 3259, VoL. 129]

\section{Scientific Aspects of Fiscal Policy}

TN a pamphlet entitled "The State and Industry 1 in 1932", printed for private circulation, Capt. Harold Macmillan, M.P., elaborates further the scientific policy which should be the natural accompaniment of the British Government's general tariff plan and the creation of the Import Duties Advisory Committee (see Nature, Feb. 20, 1932, p. 271). Capt. Macmillan directs attention to the positive aspects of this new departure in fiscal policy, to the administrative problems which it presents, and to the vital importance that the opportunities under the new policy of securing the development of our industries on deliberately planned lines should be wisely, efficiently, and expeditiously used. The administrative methods adopted make the Import Duties Advisory Committee the keystone of the structure, and upon its efficient functioning depends the success of the whole policy. Altogether apart from the abilities of those chosen for this work, there is serious danger that the Committee may become a bottle-neck rather than an efficient clearing-house, resulting in delays exasperating to the applicants and endangering precariously situated industries, or in ill-considered judgments which will later bring discredit upon the Committee and upon the policy it is endeavouring to apply.

The execution of a constructive policy which is to be prospective and not merely retrospective involves the consideration by the Committee of many involved and highly technical problems on which it will require expert advice, and Capt. Macmillan proceeds to discuss the methods by which such expert advice can be obtained from representatives of industry before blockage occurs and irreparable damage to public confidence has been done. In doing so, Capt. Macmillan stresses the complexity of the economic problems involved and the high degree of social co-ordination required for their solution.

Scientific advance and large-scale production have so knit the nation into a compact unit that almost every question is now a national question and every action taken has its repercussions through the whole economic structure. While the field of Government responsibility is constantly increasing with every effort to deal with the acute problems arising out of changes in the balance and technique of production throughout the world, the close relation of those problems to industry involves increasing dangers from bureaucratic methods. Capt. Macmillan sees in the existence of a National Government an opportunity of reviewing the whole 
situation and avoiding a drift into future difficulties, by inquiring into the whole agenda of government and, if necessary, providing new machinery.

To enable the Committee to exercise a guiding hand in the wider problems of reconstruction and to liberate it from detailed consideration of separate applications for additional duties, and at the same time to preserve industrial self-government, Capt. Macmillan suggests as the necessary liaison with industry a representative Department of Industry or an industrial sub-parliament consisting of two or three representatives from national councils for industries or groups of industries. These representatives would be available for consultation by the Import Duties Advisory Committee in its efforts to reconcile the interests of producing and consuming industries where protective measures were under discussion, following the precedent of the Dyestuffs (Import Regulation) Act, and, if unsuccessful in reaching a satisfactory agreement, would enable the necessary information to be collected and the Committee to reach a rapid decision.

This 'sub-parliament' would consider questions for the adequate discussion of which there is no present provision, including the displacement of labour through rationalisation; the balance of national production in the light of home requirements and export possibilities ; the possibilities for the expansion of certain industries and provision for contraction of others; the conditions required for the development of new industries suitable to the country ; the distribution of employment and its relation to housing, transport, road, water, gas, and electricity facilities; the gap between producers' and consumers' prices; the variation in wage rates between productive industries and sheltered services; the closer co-ordination of British financial organisation and British industry; the complementary development of British Empire production; the protection of any one industry from the high costs of inefficiency in another.

These proposals, which thus envisage the coordination of national activity in the general interests of trade and industry, are rightly regarded as involving a functional system of representation, and on this ground alone would merit the attention of scientific workers. Although some skeleton organisation already exists in the Federation of British Industries and the Association of British Chemical Manufacturers, etc., which covers the ground to a limited extent for the chief industries of Great Britain, other industries are less effectively organised for the expression of representative views.

The plea for the scientific examination of these difficult questions, for the substitution of decisions based on ascertained facts instead of opinions which may or may not be prejudiced, and, above all, for the evolution of a definite plan on national lines to which sectional interests are subordinate, must command the sympathy of all scientific workers. Their support and help will be demanded in many ways if answers are to be found to the intricate technical and scientific questions involved; and if the evolution of a planned economy involves to some extent a transition to functional representation in parliament, it will undoubtedly indicate simultaneously ways in which the knowledge and training of the scientific expert can be more effciently placed at the service of the community for the solution of the innumerable social, economic, political, and industrial problems in which vital scientific factors are involved.

\section{Social Eeonomics}

The Work, Wealth and Happiness of Mankind. By H. G. Wells. Pp. xiii $+850+32$ plates. (London: William Heinemann, Ltd., 1932.) 10s. $6 d$. net.

MR. WELLS writes of himself : " He is attempt1 ing a book, a survey of the world, a scheme and map of doing, which will enable him to say to anyone whatever: 'This is the whole world of work and wealth, of making and getting and spending, and here at this point is your place, and this is where you come in. ...", Seeking Mr. Wells's place in his own scheme, we find that he claims for his book the function of transmitting, correlating, and interpreting for the general mind the essential living thought of the world. In his "Outline of History" and "Science of Life" he attempted this task for history and for biology; now it is the turn of economics and sociology. Mr. Wells holds that mankind's ideology; or system of ideas about life in general, has become dangerously out of date, and out of correspondence with the realities of human affairs, since the " change of scale", the " abolition of distance", of the last few decades. He regards as essential for a modern ideology some understanding of world history (as against local, national, and period history), some assimilation of biological ideas, and-most urgently necessary of all-some conception of economic life, industrial processes, trade, and finance. Valiantly he has attempted to supply all three sides of this ideological triangle, and his third compendium, like its forerunners, is a remarkable, stimulating, valuable, and most readable book.

No. 3259 , VoL. 129] 